\title{
Raising awareness of chronic measurement error intrinsic to immunoassay measurements of small molecule analytes
}

\author{
Anastasia Gant Kanegusuku1, Katherine Araque ${ }^{2}{ }^{2}$, Joanna Klubo-Gwiezdzinska ${ }^{3}$ and Steven J Soldin 1,4
}

${ }^{1}$ Department of Laboratory Medicine, Clinical Center, National Institutes of Health, Bethesda, Maryland, USA, ${ }^{2}$ Pituitary Institute, Pacific Neuroscience Institute, John Wayne Cancer Institute, Santa Monica, California, USA, ${ }^{3}$ Division of Endocrinology and Metabolism, National Institute of Diabetes, Digestive and Kidney Disease, Clinical Center, National Institutes of Health, Bethesda, Maryland, USA, and ${ }^{4}$ Division of Endocrinology and Metabolism, Department of Medicine, Georgetown University, Washington,

District of Columbia, USA

In the recently published methodology editorial, 'Measurement error in clinical research, yes it matters', authors Groenwold et al. raise concerns about how measurement error and misclassification can affect the validity of biomedical studies (1). In their editorial, Groenwold et al. warn clinicians and researchers that bias due to error-prone data, for example drawing conclusions from a data set of 'self-reported' values as opposed to 'true' objectively measured values, lead to unsubstantiated claims in the literature. While it is absolutely essential to acknowledge that error can occur from many difficult-todocument variables such as BMIs or smoking habits, it is also important to point out that many of the so-called 'objective' laboratory measurements which are considered to be 'true' values are subject not only to bias, but far more importantly, to inaccuracy which is inherent in many immunoassays (thyroid hormones and cortisol are examples) and intrinsic to the method (IA) by which they are measured. Not only can these mistakenly 'objective' immunoassay measurements lead to unsubstantiated claims in the literature, more importantly, they frequently result in the misdiagnosis and mistreatment of patients in routine clinical practice. For example, high concentrations of cortisol binding globulin are associated with falsely low immunoassay cortisol measurements. These can lower what is a high cortisol by mass spectrometry after Synacthen stimulation (normal adrenal response) and be misinterpreted when the measured immunoassay result is falsely low suggesting adrenal insufficiency.
Correspondence should be addressed to S J Soldin

Email

steven.soldin@nih.gov (c) 2021 European Society of Endocrinology Printed in Great Britain
Over the past 30 years, our laboratory has documented significant discrepancies between the clinical presentation of patients suffering from thyroid or adrenal disorders, and the laboratory values obtained by immunoassay measurements of these analytes $(2,3,4,5,6,7,8,9,10)$. In these cases, when liquid chromatography-tandem mass spectrometry (LC-MS/MS) was employed, the laboratory values correlated with the clinical presentations and aided in efficient diagnoses and correct treatment (11). In a recent, currently submitted for publication study, we have found that immunoassay results for small molecule hormones (thyroxine, triiodothyronine, and cortisol) are affected by both high and low concentrations of their respective binding proteins (thyroxine-binding globulin and corticosteroid-binding globulin). As binding globulin concentrations are known to vary under conditions such as pregnancy, renal diseases and the use of commonly prescribed medications such as oral contraceptives (7) and steroids, our study brings into question the accuracy of immunoassay measurements for a large population of patients (in the USA $65 \%$ of women between 15 and 49 years of age are taking oral contraceptives) (12). Moreover, some of the commonly used supplements, like biotin, interfere with immunoassays leading to false results (13).

The clinical laboratories of many institutions opt to support their endocrinology departments by providing immunoassay-testing platforms. We urge clinicians to be wary of inaccurate immunoassay values for small molecule hormones, and to advocate for LC-MS/MS testing services

Published by Bioscientifica Ltd. 
for the measurement of thyroid hormones and cortisol, especially when laboratory values do not match the clinical presentation of the patient.

\section{Declaration of interest}

The authors declare that there is no conflict of interest that could be perceived as prejudicing the impartiality of this letter.

\section{Funding}

Relevant research on binding protein effects by the Soldin Laboratory referenced in this letter is funded by Dr Soldin's NIH Intramural Research Award.

\section{Author contribution statement}

Anastasia Gant Kanegusuku writing-original draft preparation; writingreview and editing. Katherine Araque writing-original draft preparation; writing-review and editing. Joanna Klubo-Gwiezdzinska writing-review and editing. Steven J Soldin conceptualization; resources; writing-original draft preparation; writing-review and editing.

\section{References}

1 Groenwold RHH \& Dekkers OM. Measurement error in clinical research, yes is matters. European Journal of Endocrinology 2020183 E3-E5. (https://doi.org/10.1530/EJE-20-0550)

2 Soldin OP \& Soldin SJ. Thyroid hormone testing by tandem mass spectrometry. Clinical Biochemistry 201144 89-94. (https://doi. $\operatorname{org} / 10.1016 /$ j.clinbiochem.2010.07.020)

3 van Deventer HE, Mendu DR, Remaley AT \& Soldin SJ. Inverse loglinear relationship between thyroid-stimulating hormone and free thyroxine measured by direct analog immunoassay and tandem mass spectrometry. Clinical Chemistry 201157 122-127. (https://doi. org/10.1373/clinchem.2010.154088)

4 Gounden V, Jonklaas J \& Soldin SJ. A pilot study: subclinical hypothyroidism and free thyroid hormone measurement by immunoassay and mass spectrometry. Clinica Chimica Acta: International Journal of Clinical Chemistry 2014430 121-124. (https:// doi.org/10.1016/j.cca.2013.12.034)

5 Jonklaas J, Kahric-Janicic N, Soldin OP \& Soldin SJ. Correlations of free thyroid hormones measured by tandem mass spectrometry and immunoassay with thyroid-stimulating hormone across 4 patient populations. Clinical Chemistry 200955 1380-1388. (https://doi. org/10.1373/clinchem.2008.118752)

6 Jonklaas J, Sathasivan A, Wang H, Gu J, Burman KD \& Soldin SJ. Total and free thyroxine and triiodothyronine: measurement discrepancies, particularly in inpatients. Clinical Biochemistry 201447 1272-1278. (https://doi.org/10.1016/j.clinbiochem.2014.06.007)

7 Masika LS, Zhao Z \& Soldin SJ. Is measurement of TT3 by immunoassay reliable at low concentrations? A comparison of the Roche Cobas 6000 vs. LC-MSMS. Clinical Biochemistry 201649 846-849. (https://doi.org/10.1016/j.clinbiochem.2016.02.004)

8 Parikh TP, Stolze B, Ozarda Y, Jonklaas J, Welsh K, Masika L, Hill M, DeCherney A \& Soldin SJ. Diurnal variation of steroid hormones and their reference intervals using mass spectrometric analysis. Endocrine Connections 20187 1354-1361. (https://doi.org/10.1530/EC-18-0417)

9 Haq N, Araque KA, Gant Kanegusuku AL, Wei B \& Soldin SJ. Are serum cortisol measurements by immunoassays reliable? A case series. Medical Research Archives 2020 8. (https://doi.org/10.18103/ mra.v8i5.2128)

10 Araque KA, Klubo-Gwiezdzinska J, Nieman LK, Welsh K \& Soldin SJ. Assessment of thyroid function and harmonization: opinion on thyroid hormone harmonization. Therapeutic Advances in Endocrinology and Metabolism 201910 1-4. (https://doi. org/10.1177/2042018819897049)

11 Welsh KJ \& Soldin SJ. DIAGNOSIS OF ENDOCRINE DISEASE: How reliable are free thyroid and total T3 hormone assays? European Journal of Endocrinology 2016175 R255-R263. (https://doi. org/10.1530/EJE-16-0193)

12 Daniels K \& Abma JC. Current contraceptive status among women aged 15-49: United States, 2015-2017. NCHS Data Brief, 2018. (available at: https://www.cdc.gov/nchs/products/databriefs/db327. htm). Accessed on 16 July 2020.

13 Katzman BM, Lueke AJ, Donato LJ, Jaffe AS \& Baumann NA. Prevalence of biotin supplement usage in outpatients and plasma biotin concentrations in patients presenting to the emergency department. Clinical Biochemistry 201860 11-16. (https://doi. org/10.1016/j.clinbiochem.2018.07.004)

Received 23 September 2020

Revised version received 23 September 2020

Accepted 30 September 2020 